\title{
Leaf morphological characterization and cluster analysis of Vitex negundo morphotypes
}

\author{
Florence Roy Salvaña ${ }^{1,2,3 *}$, Kenneth Eco', Nicci Rosietess Madarcos ${ }^{1}$, Nonnatus Bautista ${ }^{4}$ \\ ${ }^{1}$ Graduate School, University of the Philippines Los Baños, College, Laguna, Philippines \\ ${ }^{2}$ Philippine Council for Agriculture, Aquatic and Natural Resources Research and Development (PCAARRD), Los Baños, Laguna, \\ Philippines \\ ${ }^{3}$ Department of Biological Sciences, College of Arts and Sciences, University of Southern Mindanao, Kabacan, Cotabato \\ ${ }^{4}$ Plant Biology Division, Institute of Biological Sciences, College of Arts and Sciences, University of the Philippines Los Baños, College, \\ Laguna, Philippines \\ *Corresponding author, E-mail: rdsalvana@usm.edu.ph
}

\begin{abstract}
Addressing the unavailability of current knowledge associated with leaf morphological variations for Vitex negundo, this study aims to provide complete leaf characterization of $10 \mathrm{~V}$. negundo morphotypes. Ten mature and fully expanded leaves were randomly collected from each standing morphotype. All collected samples were characterized and measured. A dendrogram was generated using Euclidian and Unweighted Pair Group with Arithmetic Averages analysis. Distinct variation in leaf morphology among morphotypes was observed, not typical of what is known for $V$. negundo. Leaves of different morphotypes primarily differ in terms of leaf shape, apex, and base. Some morphotypes also differ from others due to the unique combination of leaf types and leaf margin. The dendrogram showed two primary clusters based on leaf shape: lanceolate and non-lanceolate leaves. Other characters such as leaf type, base, apex, abaxial surface, and margin were also essential in the formation of specific clusters and separation of $V$. negundo morphotypes. Apparent morphological variation seen among the leaves of $V$. negundo accessions revealed certain characters that are atypical for a species.
\end{abstract}

Key words: dendrogram, leaf characters, morphotypes, Vitex negundo.

Abbreviations: PaST, Paleontological Statistics; UPGMA, Unweighted Pair Group with Arithmetic Averages.

\section{Introduction}

Species of genus Vitex L. possess high morphological variation, which makes identification difficult and species delineation controversial and unclear (Phongoudome 2000; Abbas et al. 2002). One notable species of this genus is Vitex negundo L., which is a globally recognized species in terms of its pharmacological application as a cough remedy (Sofowara 2007). Four varieties of this species are validly recognized, namely, $V$. negundo var. cannabifolia, V. negundo var. microphylla, V. negundo var. negundo and $V$. negundo var. thyrsoides (Govaerts 2003). However, a complete morphological description of these four varieties and other newly established morphotypes is lacking. As a result, other unresolved and illegitimate varieties used in various studies emerged which makes identification more complicated.

Leaf morphological characters are one of the essential components of species and even morphotype identification and classification. These characters have been utilized as an aid in taxon delimitation and some of these characters are often included in identification field guides and handbooks (Poland, Clement 2009; Stace 2010). Several studies have also used leaf characters to reiterate infraspecific variation, which include leaf ratio and petiole length (Cao et al. 2011), and micromorphological characters and patterns such as trichomes and stomata (Bugg et al. 2013; Devecchi et al. 2014; Carlson et al. 2016).

Based on recent records, there are 10 standing germplasm collections of $V$. negundo in the Philippines (Department of Agriculture 1995). A preliminary study conducted provided morphological characteristics of four morphotypes (Comandante 2008); however, some were changed and new morphotypes were added. This study entails the description of leaf morphological characters of different $V$. negundo morphotypes. It is crucial to have a correct characterization of the different morphotypes since the species is known to be essential due to its medicinal importance. In determining which of these morphotypes yield higher levels of bioactive compounds, proper identification is needed wherein these leaf morphological descriptions is of great help. Industries using this plant for commercial production of plant-based medicine will have an idea what specific morphotypes are best suited for production. 


\section{Materials and methods}

\section{Collection of leaf samples}

Leaf samples of Vitex negundo L. morphotypes were collected from the standing germplasm collections planted in the National Plant Genetic Resource Laboratory, Institute of Plant Breeding, College of Agriculture and Food Science, Los Baños, Laguna, Philippines (14ㅇ'⒗6896” N, $\left.121^{\circ} 15^{\prime} 47.0988^{\prime \prime}\right)$. The area has a local steppe climate with an average annual temperature is $16.5^{\circ} \mathrm{C}$ and an average precipitation of $229 \mathrm{~mm}$. Ten mature and fully expanded leaves were randomly collected in each standing collection.

\section{Leaf characterization}

All collected samples were examined and characterized. The number of leaflets in each sample was counted. Basic morphological characteristics of the leaves, such as leaf type, shape, margin, apex, and base, were described based on established leaf description manuals. The colour of adaxial and abaxial surfaces was noted. Measurements, such as leaflet length and width and petiole length, were done using a ruler or dial caliper. Examined samples were pressed and dried for voucher specimens and were deposited in the herbarium.

\section{Cluster analysis}

Cluster analysis was done using PaST - Paleontological Statistic ver. 1.64 (Hammer et al. 2007) to analyze differences among morphotypes. Some characters were selected and each of its character states was assigned as values corresponding to a legend as seen in Table 1. A dendrogram was constructed using Euclidian as a distance measure and Unweighted Pair Group with Arithmetic Averages (UPGMA) as a linkage method.

\section{Results}

\section{Leaf morphological description of 10 Vitex negundo morphotypes}

Leaf characters including leaf shape, apex and base vary among $V$. negundo morphotypes were examined (Table 2). Most of the morphotypes had lanceolate to ellipticlanceolate leaves, however, GB 59670 and GB 59671 differed with obovate to oblanceolate leaves. Six morphotypes had an acuminate leaf apex and three had an acute apex. GB 63323 had an acute-acuminate leaf apex. Moreover, six morphotypes had an acute leaf base; two had an attenuate; one had an attenuate-oblique; one had an acute-oblique and another one had an acute-cuneate. Both GB 59670 and GB 59671 had trifoliate leaves, however, simple leaves also occured in GB 59670, which were observed in young shoots. Other morphotypes had 3 to 5 leaflets, which occured in one individual. Leaves of all morphotypes had a green adaxial and light-green abaxial surface. The abaxial surface of GB 59670 and GB 59671 leaves was glabrous, which indicates high density of trichomes.

GB 58245. Medium-sized shrub up to $5 \mathrm{~m}$ tall. Leaves opposite, palmately compound with 3 - 5 leaflets, longer leaflet $7.3-10.0 \times 1.3-1.9 \mathrm{~cm}$, smaller leaflets $4.9-6.0 \times$ $1.0-1.4 \mathrm{~cm}$; lanceolate, acuminate apex, acute base, entire margin; adaxial green, abaxial light green, smooth; petiolate $3.0-3.9 \mathrm{~cm}$ (Fig. 1).

GB 59550. Medium-sized shrub up to $5.0-5.7 \mathrm{~m}$ tall. Leaves opposite, palmately compound with $3-5$ leaflets,

Table 1. The analyzed leaf characters and character states of Vitex negundo morphotypes

\begin{tabular}{|c|c|c|c|c|c|c|}
\hline \multirow[t]{9}{*}{ Morphotype } & Type & Shape & Margin & Apex & Base & Abaxial surface \\
\hline & 0 palmately & 0 lanceolate; 1 & 0 entire; & 0 acute; & 0 acute; & 0 smooth; \\
\hline & compound; & obovate; & 1 entire- & 1 acuminate; & 1 acute-cuneate; & 1 glabrous \\
\hline & 1 trifoliate; & 2 elliptic-elliptic & irregularly & 2 acute- & 2 attenuate; & \\
\hline & 2 trifoliate- & lanceolate; & serrated; & acuminate) & 3 attenuate- & \\
\hline & palmate; & 3 elliptic- & 2 sererated & & oblique & \\
\hline & 3 simple & lanceolate; & & & & \\
\hline & trifoliate & 4 obovate- & & & & \\
\hline & & oblanceolate & & & & \\
\hline GB 59706 & 2 & 3 & 0 & 1 & 3 & 0 \\
\hline GB 58245 & 0 & 0 & 0 & 1 & 0 & 0 \\
\hline GB 59670 & 3 & 1 & 0 & 0 & 1 & 1 \\
\hline GB 59918 & 0 & 0 & 1 & 1 & 2 & 0 \\
\hline GB 59550 & 1 & 0 & 0 & 0 & 0 & 0 \\
\hline GB 59856 & 0 & 0 & 2 & 1 & 0 & 0 \\
\hline GB 59685 & 0 & 2 & 0 & 0 & 2 & 0 \\
\hline GB 63323 & 0 & 0 & 0 & 2 & 0 & 0 \\
\hline GB 59671 & 1 & 4 & 0 & 0 & 0 & 0 \\
\hline GB 59811 & 0 & 0 & 0 & 1 & 0 & 0 \\
\hline
\end{tabular}




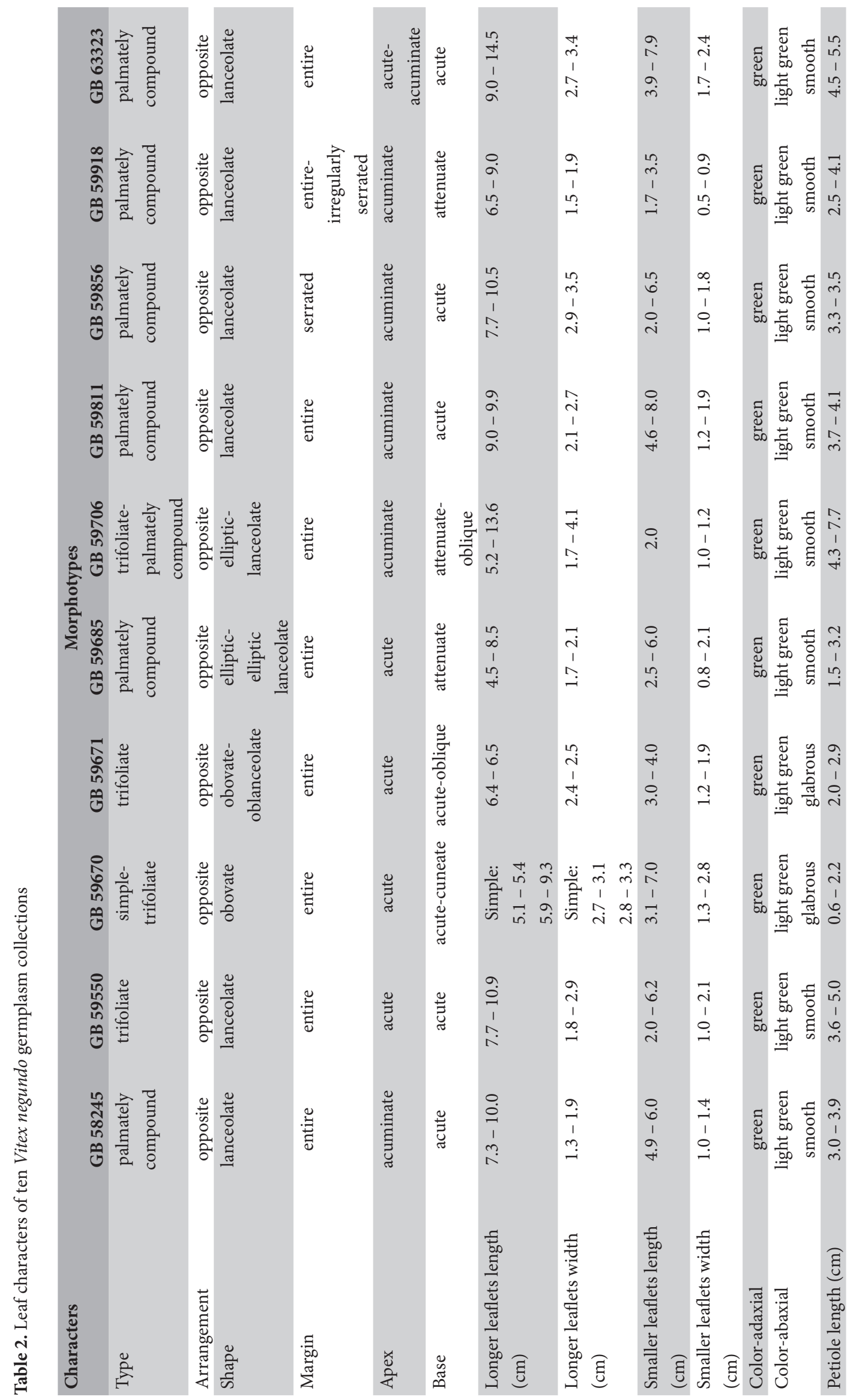



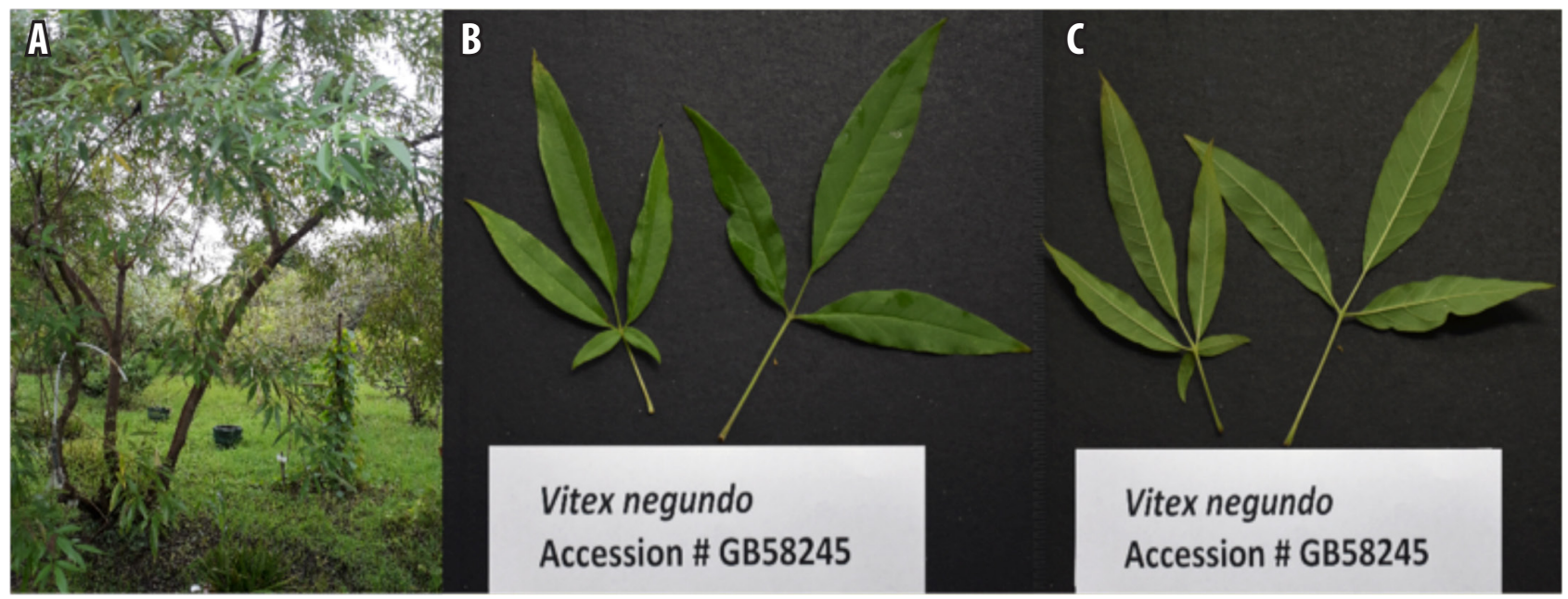

Fig. 1. Growth habit (A) and leaves of Vitex negundo GB 58245 showing adaxial (B) and abaxial (C) portions.
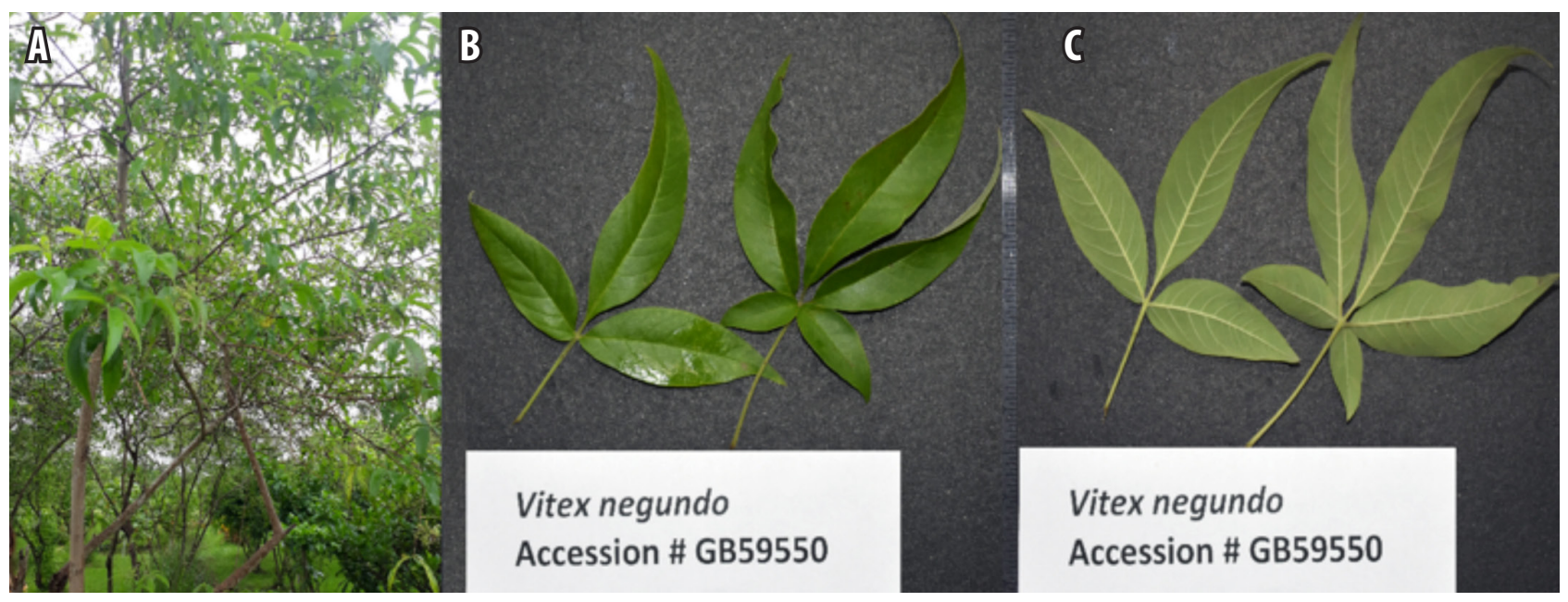

Fig. 2. Growth habit (A) and leaves of Vitex negundo GB 59550 showing adaxial (B) and abaxial (C) portions.
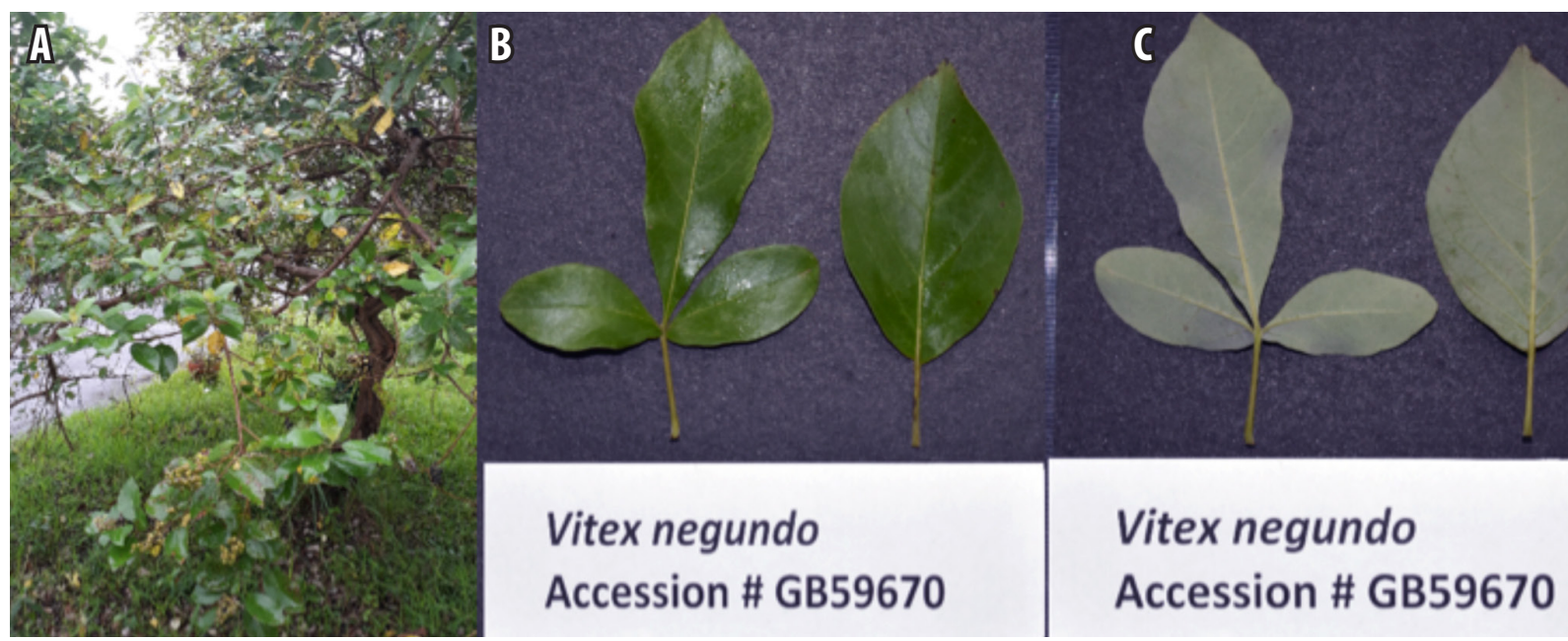

Fig. 3. Growth habit (A) and leaves of Vitex negundo GB 59670 showing adaxial (B) and abaxial (C) portions.

longer leaflet $7.7-10.9 \times 1.8-2.9 \mathrm{~cm}$, smaller leaflets 2.0 $-6.2 \times 1.0-2.1 \mathrm{~cm}$; lanceolate, acute apex and base, entire margin; adaxial green, abaxial light green, smooth; petiolate

\section{$3.6-5.0 \mathrm{~cm}$ (Fig. 2).}

GB 59670. Small shrub up to $2-2.4 \mathrm{~m}$ tall. Leaves opposite, simple or trifoliate, simple leaf $5.1-5.4 \times 2.7-3.1$ 

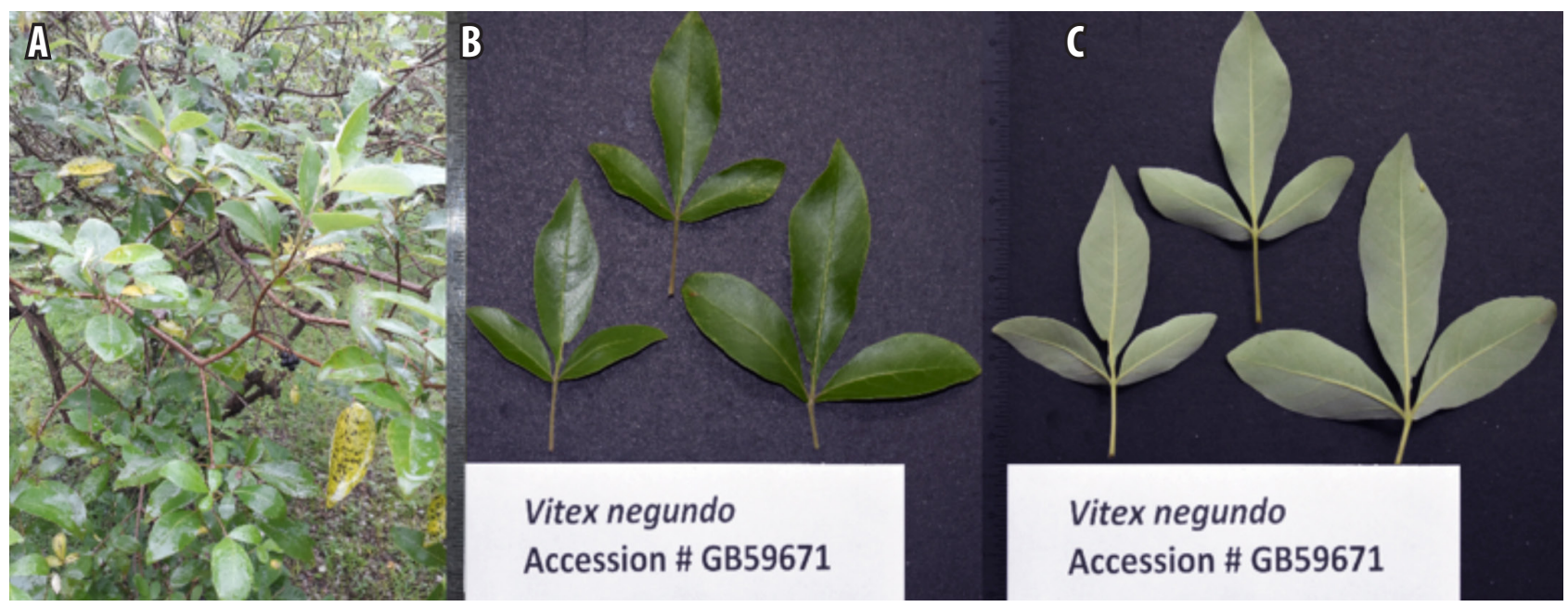

Fig. 4. Growth habit (A) and leaves of Vitex negundo GB 59671 showing adaxial (B) and abaxial (C) portions.

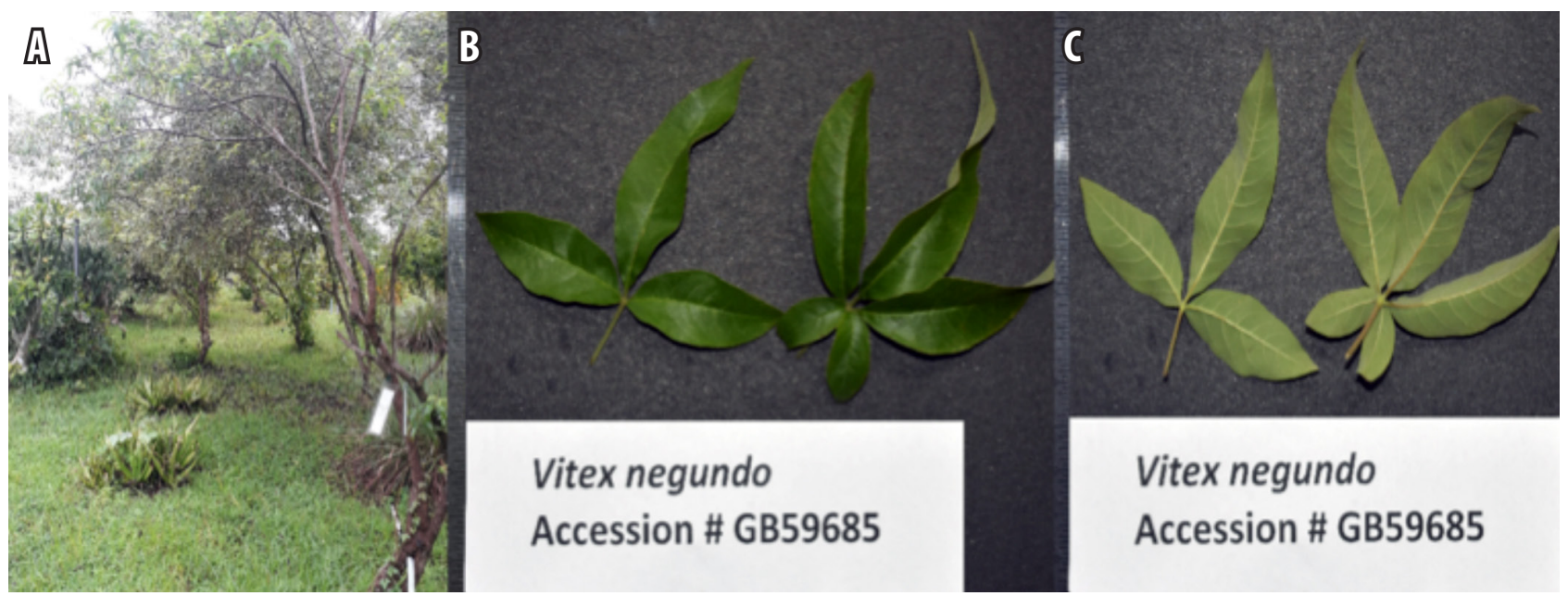

Fig. 5. Growth habit (A) and leaves of Vitex negundo GB 59685 showing adaxial (B) and abaxial (C) portions.

$\mathrm{cm}$; trifoliate leaf with longer leaflet $5.9-9.3 \times 2.8-3.3 \mathrm{~cm}$, smaller leaflets $3.1-7 \times 1.3-2.8 \mathrm{~cm}$; obovate, acute apex, acute-cuneate base, entire margin; adaxial green, abaxial light green, glabrous; petiolate $0.6-2.2 \mathrm{~cm}$ (Fig. 3)

$G B$ 59671. Small shrub up to $2.0-2.3 \mathrm{~m}$ tall. Leaves opposite, trifoliate, longer leaflet $6.4-6.5 \times 2.4-2.5$ $\mathrm{cm}$, smaller leaflets $3.0-4.0 \times 1.2-1.9 \mathrm{~cm}$; obovateoblanceolate, acute apex, acute-oblique base, entire margin; adaxial green, abaxial light green, glabrous; petiolate 2.0 $2.9 \mathrm{~cm}$ (Fig. 4).

GB 59685. Medium-sized shrub up to $3.5-4.2 \mathrm{~m}$ tall. Leaves opposite, palmately compound with 3 - 5 leaflets, longer leaflet $4.5-8.5 \times 1.7-2.1 \mathrm{~cm}$, smaller leaflets 2.5 - $6.0 \mathrm{~cm} \times 0.8-2.1 \mathrm{~cm}$; elliptic-elliptic- lanceolate, acute apex, attenuate base, entire margin; adaxial green, abaxial light green, smooth; petiolate $1.5-3.2 \mathrm{~cm}$ (Fig. 5).

GB 59706. Medium-sized shrub up to $4.0-4.5 \mathrm{~m}$ tall. Leaves opposite, palmately compound with 2 distinctly smaller leaflets $2.0 \times 1.0-1.2 \mathrm{~cm}$, longer leaflets $5.2-13.6 \times$ $1.7-4.1 \mathrm{~cm}$; elliptic-lanceolate, acuminate apex, attenuate- oblique base, entire margin; adaxial green, abaxial light green, smooth; petiolate $4.3-7.7 \mathrm{~cm}$ (Fig. 6).

GB 59811. Medium-sized shrub up to $3.0-3.6 \mathrm{~m}$ tall. Leaves opposite, palmately compound with 5 leaflets, longer leaflet $9.0-9.9 \times 2.1-2.7 \mathrm{~cm}$, smaller leaflets $4.6-8.0 \times$ $1.2-1.9 \mathrm{~cm}$; lanceolate, acuminate apex, acute base, entire margin; adaxial green, abaxial light green, smooth; petiolate $3.7-4.1 \mathrm{~cm}$ (Fig. 7).

GB 59856. Medium-sized shrub up to $3-3.4 \mathrm{~m}$ tall. Leaves opposite, palmately compound with 5 leaflets, longer leaflet $7.7-10.5 \times 2.9-3.5 \mathrm{~cm}$, smaller leaflets $2.0-6.5 \times$ $1.0-1.8 \mathrm{~cm}$; lanceolate, acuminate apex, acute base, serrate margin; adaxial green, abaxial light green, smooth; petiolate $3.3-3.5 \mathrm{~cm}$ (Fig. 8).

GB 59918. Medium-sized shrub up to $3.0-3.2 \mathrm{~m}$ tall. Leaves opposite, palmately compound with 2 distinctly smaller leaflets $1.7-3.5 \times 0.5-0.9 \mathrm{~cm}$, longer leaflets 6.5 - $9.0 \times 1.5$ - $1.9 \mathrm{~cm}$; lanceolate, acuminate apex, attenuate base, entire margin with irregular serrations; adaxial green, abaxial light green, smooth; petiolate $2.5-4.1 \mathrm{~cm}$ (Fig. 9). 

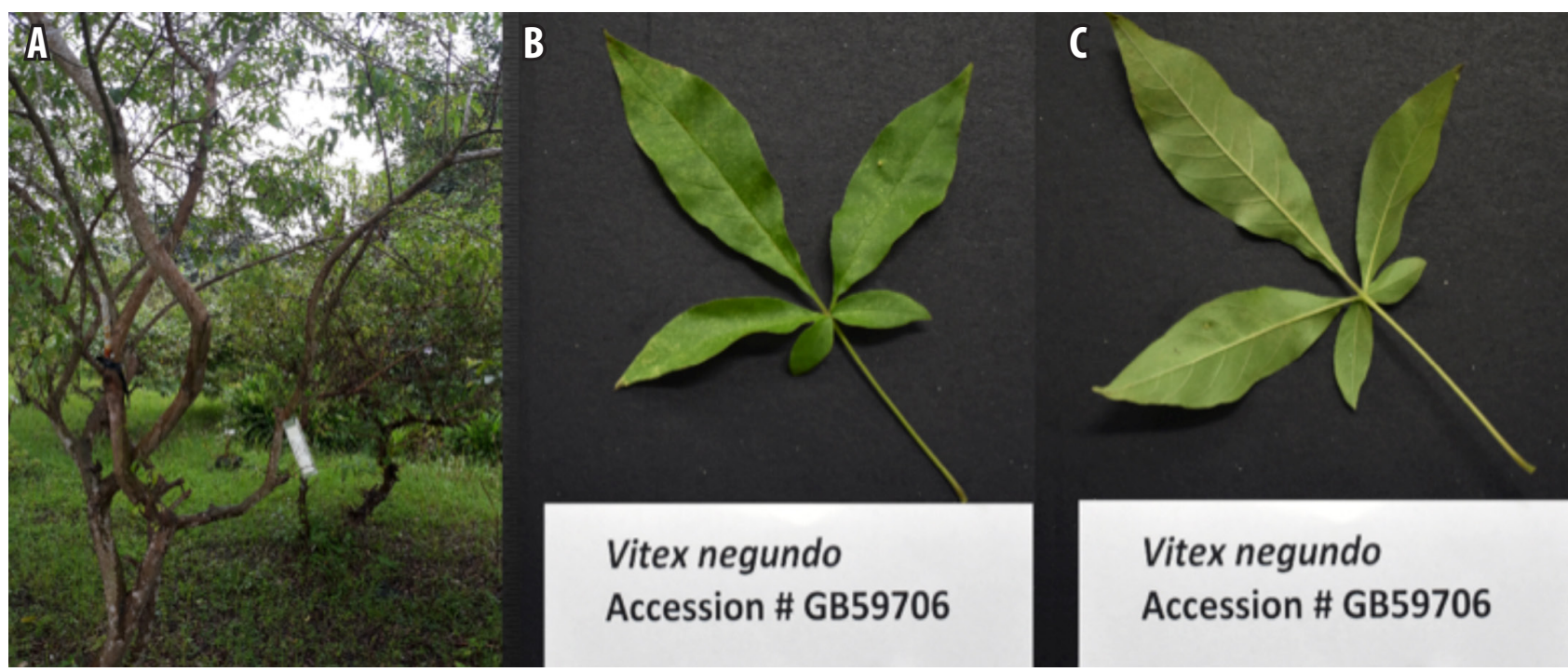

Vitex negundo Accession \# GB59706

Fig. 6. Growth habit (A) and leaves of Vitexnegundo GB 59706 showing adaxial (B) and abaxial (C) portions.
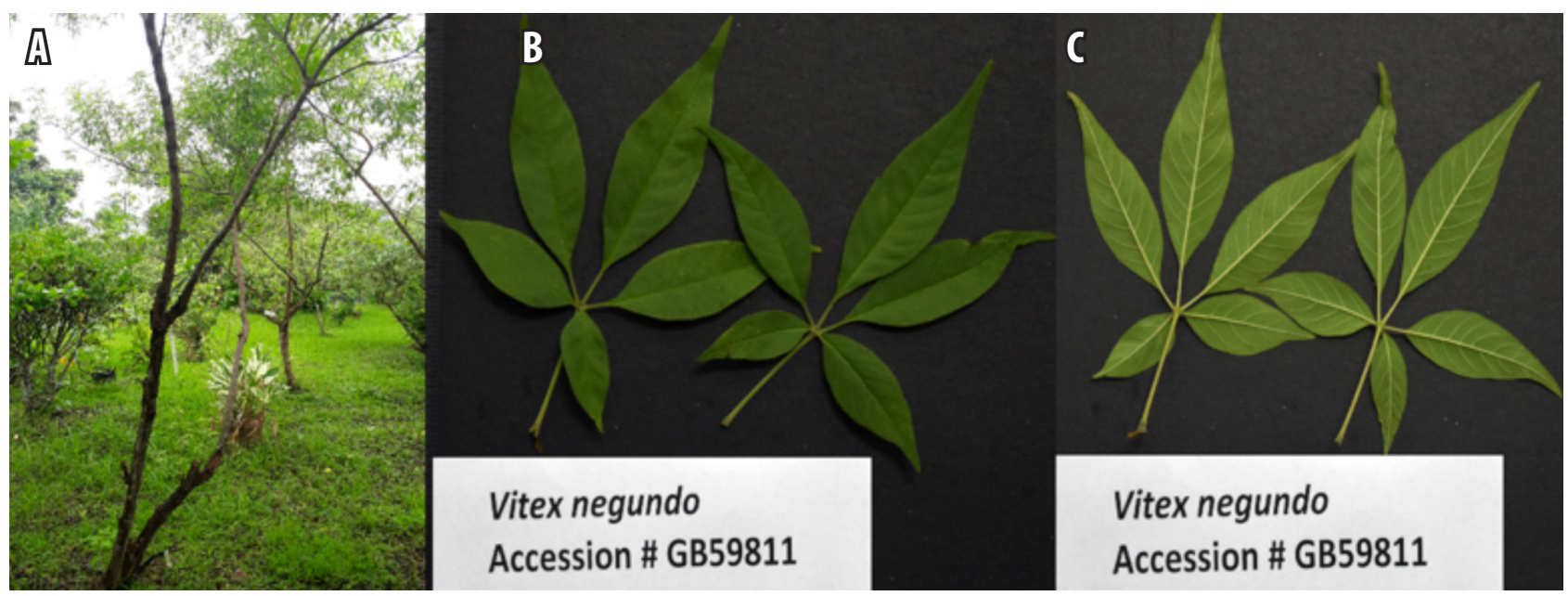

Fig.7. Growth habit (A) and leaves of Vitex negundo GB 599811 showing adaxial (B) and abaxial (C) portions.
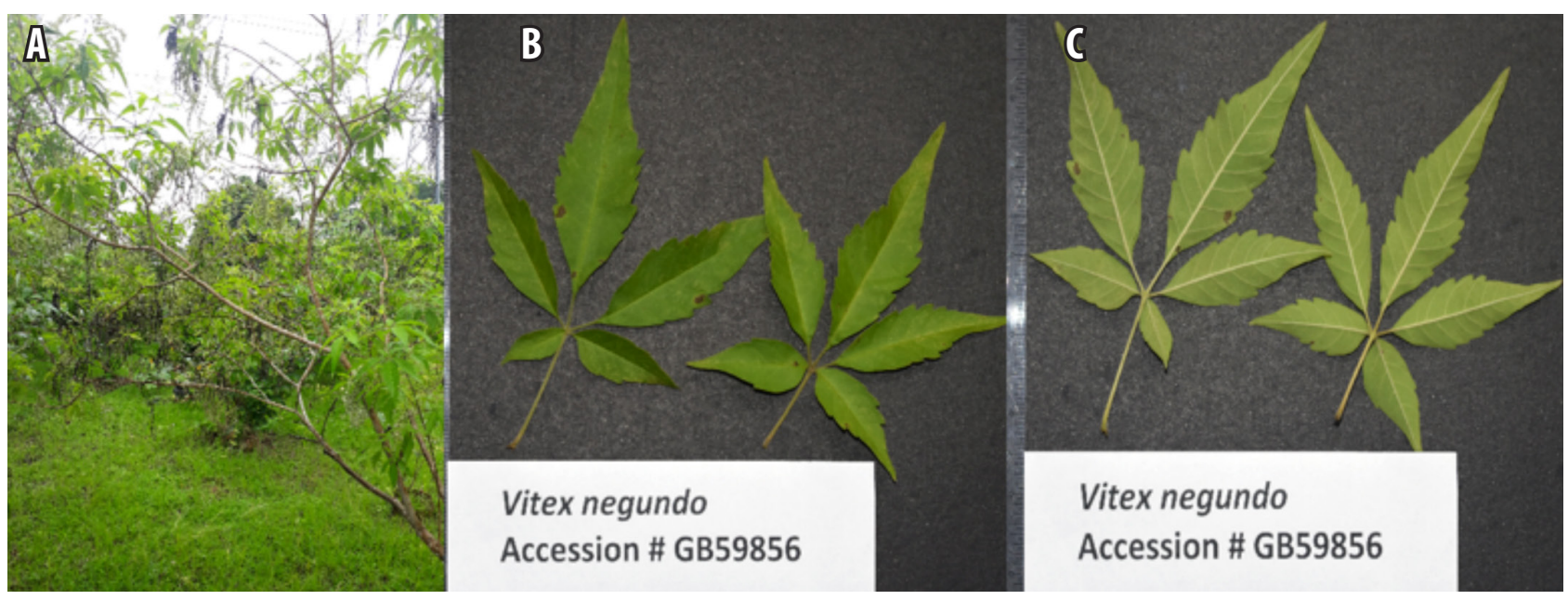

Fig. 8. Growth habit (A) and leaves of Vitex negundo GB 59856 showing adaxial (B) and abaxial (C) portions. 


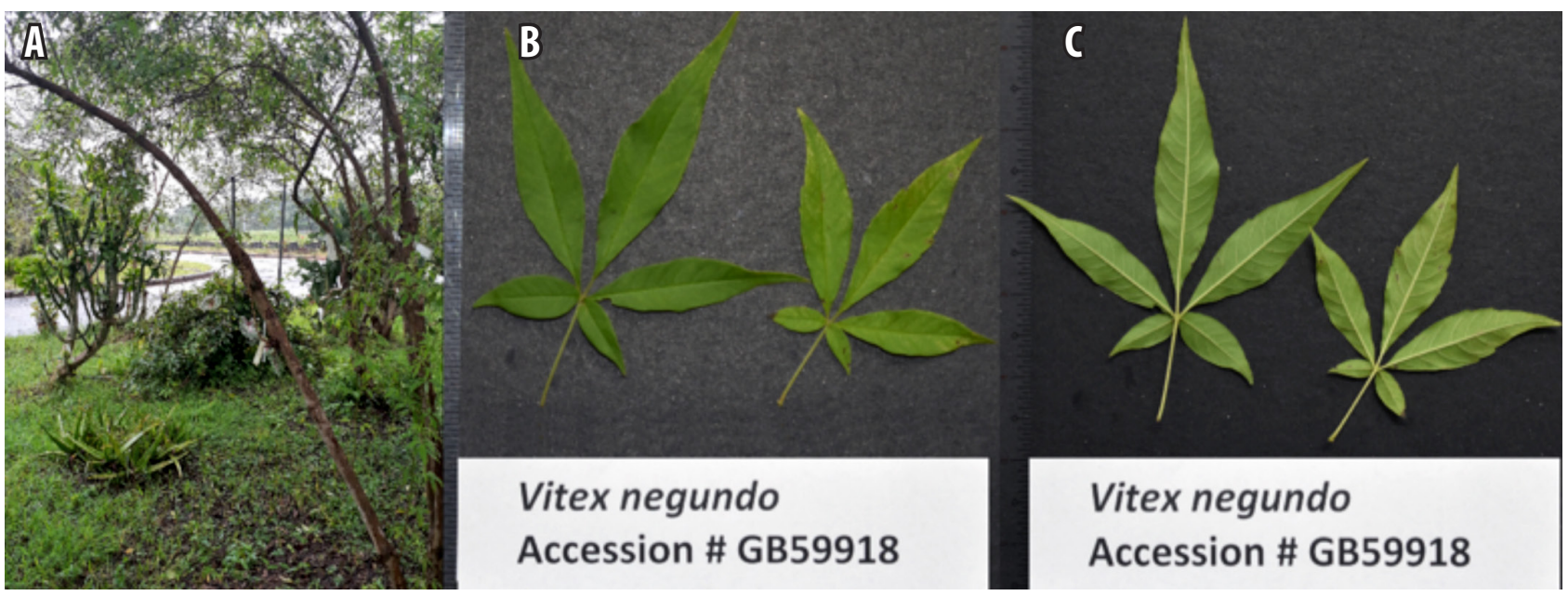

Fig. 9. Growth habit (A) and leaves of Vitex negundo GB 59918 showing adaxial (B) and abaxial (C) portions.
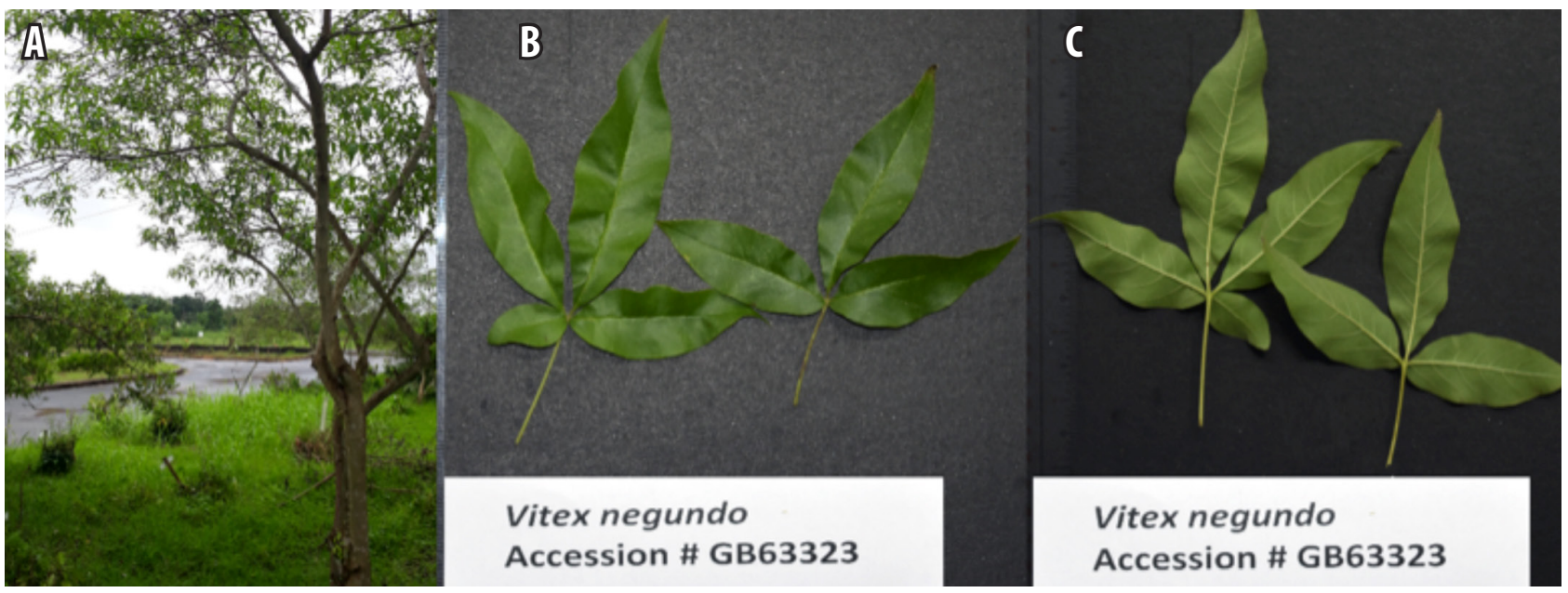

Fig. 10. Growth habit (A) and leaves of Vitex negundo GB 63323 showing adaxial (B) and abaxial (C) portions.

GB 63323. Medium-sized shrub up to $4-5 \mathrm{~m}$ tall. Leaves opposite, palmately compound with 3 - 4 leaflets, longer leaflet $9.0-14.8 \times 2.7-3.4 \mathrm{~cm}$, smaller leaflets $3.9-7.9 \times$ $1.7-2.4 \mathrm{~cm}$; lanceolate, acute-acuminate apex, acute base, entire margin; adaxial green, abaxial light green, smooth; petiolate $4.5-5.5 \mathrm{~cm}$ (Fig. 10).

\section{Cluster analysis}

Leaf morphological characters including leaf types, shape, margin, apex, base and abaxial surface were subjected to cluster analysis. The dendrogramme showed two major clusters (Fig. 11). Two clusters were formed primarily based on the leaf shape, lanceolate and non-lanceolate. GB 59918, GB 59856, GB 59550, GB 63323, GB 58245 and GB 59811 had lanceolate leaves while GB 59670, GB 59671, GB 59685 and 59706 had non-lanceolate leaves. Clustering of GB 59670, GB 59671, GB 59685 and GB 59706 was supported by a similar leaf margin. Moreover, GB 58245 and GB 59811 formed one cluster. These two morphotypes had similar character states in all qualitative characters.

\section{Discussion}

Most of the morphological variations observed from the examined leaf samples include the sizes of the leaflets, petiole length, leaf type shape, apex, base, and margin. These and other leaf characters have been used in detailed and well-illustrated publications in order to provide a holistic description of a specific taxonomic rank (Ellis et al. 2009; Goncalves, Lorenzi 2011). Despite this, leaf characters are often neglected due to the fact that these characters are easily affected by environmental fluctuations and considering phenotypic plasticity. Some environmental variables have been associated with the variation in leaf forms of some species. The full potential of these characters remains relatively unexplored even though there are already works suggesting their effectiveness. This should not override the fact that these characters are easily observable. More often than not, plant identity is based on leaf morphological characters, especially for field-based assessment. Some field studies suggest that leaf characters are of great importance 


\section{A}

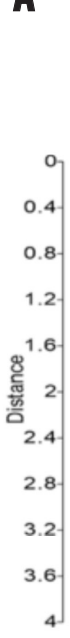

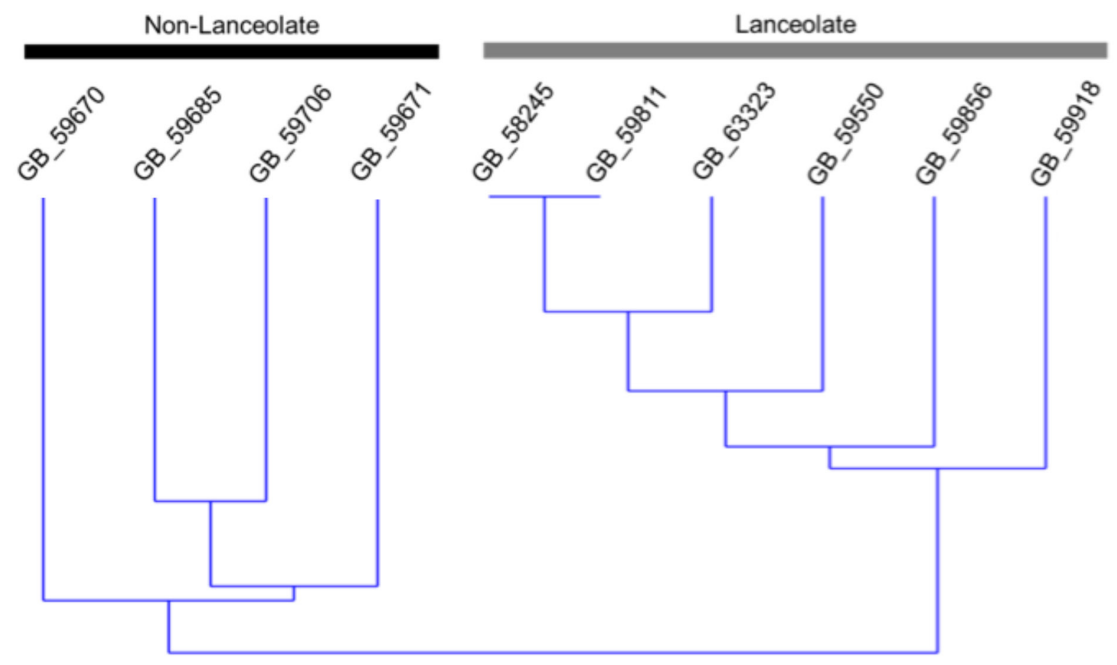

B

$\begin{array}{llllllll}1 & 2 & 3 & 4 & 0 & 0 & 0 & 0 \\ 3 & 0 & 2 & 1 & 0 & 0 & 0 & 1 \\ 1 & 2 & 3 & 0 & 0 & 0 & 0 & 0 \\ 0 & 0 & 1 & 0 & 1 & 1 & 2 & 0 \\ 1 & 0 & 0 & 1 & 0 & 0 & 0 & 0 \\ 0 & 0 & 0 & 0 & 0 & 0 & 0 & 0\end{array}$

$\begin{array}{ll}0 & 0 \\ 0 & 0 \\ 0 & 2 \\ 1 & 1 \\ 0 & 0 \\ 2 & 1\end{array}$

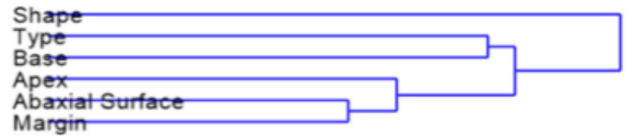

Fig. 11. A, dendrogram of Vitex negundo morphotypes showing two major clusters (1 - non-lanceolate leaves; 2 - lanceolate leaves) with Euclidian distance of 4. B, two-way analysis using showing characters used to separate morphotypes.

in taxonomic studies, particularly in sterile plants and fossils without reproductive parts (Hickey, Taylor 1991). It was also pointed out that leaf characters are geneticallyfixed characters (Roth-Nebelsick et al. 2001).

This study also assessed variations of the leaf characters of ten $V$. negundo germplasm collections using a set of character states. There have been various taxonomic controversies resolved using these characters. Some of these include the use of leaf form and venation in determining differences of Sorbus leaf types (Merrill 1978); leaf shapes as the fundamental species difference in oaks (Jensen 1990); leaf architecture in the delineation of three subgenera of Ficus (Loufty et al., 2005); three controversial species of Hoya (Hoya coriacea, Hoya halconensis and Hoya boutii; Salvaña, Buot 2014); classification of Camellia species (Lu et al. 2012); and in species separation of Salicaceae through continuous foliar characters (Theibaut 2000).

Leaf morphometric analysis have been used in order to characterize and elucidate infraspecific variants and morphotypes. It can be noted that the measurement and the quantitative relations of patterns of phenotypic variations within and between species and infraspecific ranks have been applied in plant morphometrics (Pearson 1901). Furthermore, utilization of a wide range of morphometric measurements have been used traditionally. Marcus (1990) stated that this technique employs a suitable multivariate statistical analysis to analyze more than one trait to be able to generate patterns of phenotypic variations. In addition, Ray (1992) applied morphometric analysis in separating species of Syngonium (Araceae) particularly through leaf shape contours and other homologous features.

Some qualitative leaf characters and character states of the ten V. negundo germplasm collections were subjected to cluster analysis. Cluster analysis is a statistical tool which produces a hierarchical classification of taxa based on similarity matrix (Hambrick 1984). The Unweighted Pair Group Method with Arithmetic Averages (UPGMA) is a clustering approach and was used in this analysis. UPGMA algorithm constructs a dendrogram that reflects the structure present in a pairwise similarity matrix and clusters are joined based on the average distance between the members of a group (Sokal, Michener 1958). Apparently, the dendrogram produced by this approach depicts the same pattern of clusters to other approaches. Hammer et al. (2007) stated that if the groupings do not change when trying another algorithm, that grouping should be trusted. UPGMA clustering has been used in the classification of some medicinal representatives of the tribe Areae (Araceae) (Sun et al. 2000), for selected species of Philippine Cinnamomum based on venation patterns (Celadiña et al. 2012); and to characterize similarities between Psychotria (subg. Heteropsychotria) and Palicourea species (Da Silva et al. 2011).

\section{Conclusions}

Leaf characters are essential in elaborating morphological variation of ten standing germplasm collection of V.negundo in the Philippines. Foliar description of each morphotype can be a helpful tool in resolving taxonomic discrepancies 
and identification of morphotypes. In addition, it can provide valid answers on problems related to varied results on phytochemical studies that may cause confusion on the accurate compounds present in the species. This study highlighted the utilities of leaf characters, which can be used in a wide range of studies, especially for identification.

\section{Acknowledgements}

The researchers would like to express their heartfelt gratitude to those who one way another helped in the completion of this study especially to Maria Leah H. Villavicencio and Dr. Laverne S. Gueco of National Plant Genetic Resources Laboratory, Institute of Plant Breeding, College of Agriculture and Food Sciences, University of the Philippines Los Baños, College, Laguna, Philippines.

\section{References}

Abbas Azimi R., Jamzad Z., Sefidkon F., Bakhshi-Khaniki G. 2002. The potential value of phytochemical and micromorphological characters in taxonomic treatment of genus Vitex L. (Lamiaceae). Iran. J. Bot. 12: 15-35.

Bugg C.C., Smith N., Blackstock D., Simpson M., Ashton P. 2013. Consistent and variable leaf anatomical characters in Carex (Cyperaceae). Bot. J. Linn. Soc. 172: 371-384.

Cao E.P., Valenzuela A.J.F., Santos B.S., Quilang J.P. 2011. Comparative use of meristic and geomorphometric analyses of vegetative and floral characters in studying intraspecific variation in Portulaca grandiflora (Hook). Sci. Diliman 23: 41-53.

Carlson J.E., Adams C.A., Holsinger K.E. 2016. Intraspecific variation in stomatal traits, leaf traits and physiology reflect adaptation along aridity gradients in a South African shrub. Ann. Bot. 117: 195-207.

Celadiña D., Buot I.E., Madulid D.A., Evangelista T., Tandang D. 2012. Leaf architecture of selected Philippine Cinnamomum Schaeff. (Lauraceae) Species. Thailand Nat. Hist. Museum J. 6: 89-111.

Comandante J.D. 2008. Morpho-anatomical, phytochemical and cytotoxicity studies on selected local varieties of Lagundi, Vitex negundo L. (Lamiaceae). Undegraduate Thesis.

Da Silva Moraes T.M., Rabelo G.R., Alexandrino C.B., da Silva Neto S.J., Cunha M.D. 2011. Comparative leaf anatomy and micromorphology of Psychotria species (Rubiaceae) from the Atlantic Rainforest. Acta Bot. Bras. 25: 178-190.

Department of Agriculture (Philippines). 1995. Philippines: Country Report to the FAO International Technical Conference on Plant Genetic Resources.

Devecchi M.F., Pirani J.R, de Albuqueque Melo-de-Pinna G.F. 2014. Comparative leaf anatomy and morphology of some Brazilian species of Crotalaria L. (Leguminosae: Papilionoideae: Crotalarieae). Acta Bot. Bras. 28: 583-593.

Ellis B., Daly D.C., Hickey L.J., Johnson K.R., Mitchell J.D., Wilf P., Wing S.L. 2009. Manual of Leaf Architecture. Cornell University Press, Ithaca, New York, USA.

Gonçalves E.G., Lorenzi H. 2011. Morfologia Vegetal. Organografia e dicionário ilustrado de morfologia das plantas vasculares. $2^{\text {nd }}$ ed. Instituto Plantarum de Estudos da Flora Ltda, Nova Odessa.

Govaerts R. 2003. World Checklist of Selected Plant Families Database in ACCESS: 1-216203. The Board of Trustees of the Royal Botanic Gardens, Kew.

Hambrick D. C. 1984. Taxonomic approaches to studying strategy: Some conceptual and methodological issues. J. Manage. 10: 27-41.

Hammer O., Harper D.A.T., Ryan P.D. 2007. PaST- Paleontological Statistics ver. 1.64. http://folk.uio.no/ohammer/past.

Hickey L.J., Taylor D.W. 1991. The leaf architecture of Ticodendron and application of foliar characters in discerning its relationships. Ann. Missouri. Bot. Gard. 78: 105-130.

Jensen R.J. 1990. Detecting shape variation in oak-leaf morphology, a comparison of rotational fit methods. Am. J. Bot. 77: 1279-1293.

Loufty M.H.A., Karakis E.A.K., Khalifa S.F., Mira E. 2005. Numerical taxonomic evaluation of leaf architecture of some species of genus Ficus L. Int. J. Agric. Biol. 7: 352-357.

Lu H., Jiang W., Ghiassi M., Lee S., Nitin M. 2012. Classification of Camellia (Theaceae) species using leaf architecture variations and pattern recognition techniques. PLoS ONE 7: e29704.

Marcus L.F. 1990. Traditional morphometrics. In: Rohlf F.J., Bookstein F.L.(eds) Proceedings of the Michigan Morphometrics Workshop. University of Michigan Museum of Zoology. Ann Arbor. 2: 77-122.

Merrill E.K. 1978. Comparison of mature leaf architecture of three types of Sorbus L. (Rosaceae). Bot. Gaz. 139: 447-453.

Pearson K. 1901. On lines and planes of closest fit to systems of points in space. Phil. Mag. 2: 559-572.

Phongoudome C. 2000. A systematic study on Vitex Tourn (Verbenaceae) in Sabah and Sarawak., Malaysia. Ph.D. dissertation, University Putra Malaysia.

Poland J., Clement E. 2009. Vegetative Key to the British Flora. Botanical Society of the British Isles.

Ray T.S. 1992. Landmark eigenshape analysis: homologous contours: leaf shape in Syngonium (Araceae). Am. J. Bot. 79: 69-76.

Rechinger K.H. 1967. Verbenaceae. In: Patzak A., Rechinger K.H. (eds). Flora Iranica. No. 47.

Roth-Nebelsick A., Uhl D., Morsbrugger V., Kerp H. 2001. Evolution and function of leaf venation architecture: A review. Ann. Bot. 87: 553-566.

Salvaña F.R.P., Buot I.E. 2014. Leaf architectural study of Hoya coriacea, Hoya halconensis and Hoya buotii (Apocynaceae). Int. Res. J. Biol. Sci. 3: 37-44.

Sofowora A. 2008. Medicinal Plants and Traditional Medicine in Africa. $3^{\text {rd }}$ ed. Spectrum Books Limited, Ibadan, Nigeria, pp. 199-204.

Sokal R.R., Michener C. 1958. A statistical method for evaluating systematic relationships. Univ. Kans Sci. Bull. 38: 1409-1438.

Stace C. 2010. New Flora of the British Isles. $3^{\text {rd }}$ ed. Cambridge: Cambridge University Press.

Sun H., Xue X., Ye Y. 2000. Numerical taxonomy of medicinal plants from areae in Zhejiang Province. J. Chinese Medic. Mater. 23: 735-738.

Theibaut M. 2000. A foliar morphometric approach to the study of Salicaceae. Bot. Rev. 66: 423-439. 